\title{
Adolescent identity formation and internet usage
}

\author{
MUKTA GARG AND PREETI YADAV
}

Received: 26.01.2015; Revised: 06.04.2015; Accepted: 21.04 .2015

See end of the paper for authors' affiliations MUKTA GARG

Department of Human

Development and Family Studies,

College of Home Science, C.S.A.

University of Agriculture and

Technology, KANPUR (U.P.) INDIA

Email : mukta.garg@yahoo.com
ABSTRACT : Globalization has brought sweeping changes in socio-economic-cultural realms in our society. One of the ways in which human beings are influenced by globalization is through technology, of which the internet has a wider reach than any other medium. The phenomenon of the internet has created 'virtual spaces' in which adolescents spend increasing amounts of time. This study on adolescent identity formation and internet usage was conducted on a random sample of 120 (60 respondents were boys and 60 were girls) adolescent from different technical institutes of Kanpur city. It was found that 90.83 per cent respondents use computer at home and maximum respondents were interested in facebook on internet, whereas, 78.33 per cent respondents give their opinion that internet give latest information, current affairs, latest update etc. and 71.66 per cent respondents give their opinion that internet increase their knowledge. The finding shows that 75.83 per cent respondents think that cyber and pornography increase higher rate of sexual aggression and greater risk of teenage pregnancy, 70 per cent respondents think that internet play an important role in their physical development, while 67.5 per cent of respondents stated that internet has a important in their identity formation, whereas, 66.66 per cent respondents think that internet create a platform of cyber bullying as well as 65 per cent of respondents satisfied with the present resources and opportunities.

KEY WORDS: Adolescent, Identity formation, Internet

- HOW TO CITE THIS PAPER : Garg, Mukta and Yadav, Preeti (2015). Adolescent identity formation and internet usage. Asian J. Home Sci., 10 (1) : 129-132. 